\title{
INITIAL COMMISSIONING RESULTS OF THE RTA INJECTOR
}

\author{
S. Eylon, E. Henestroza, S.M. Lidia, D.L. Vanecek, S.S. Yu, LBNL, Berkeley, CA; \\ T.L. Houck, G.A. Westenskow, LLNL, Livermore, CA; \\ D.E. Anderson, LANL, Los Alamos, NM
}

\begin{abstract}
The creation of the drive beam remains one of the most challenging technical endeavours in constructing two-beam accelerators. We have begun testing the $1.2-\mathrm{kA}, 1.0-\mathrm{MeV}$ electron induction injector for the RTA experiment. The electron source is a 3.5 -inch diameter, thermionic, flat-surface cathode with a maximum shroud field stress of approximately $165 \mathrm{kV} / \mathrm{cm}$. The pulse length of the injector is approximately $250 \mathrm{~ns}$, with a 120-ns flattop region. We report here measurements of the pulsed power system performance, beam voltage and current. Plans to measure the emittance and current density profile are discussed.
\end{abstract}

\section{INTRODUCTION}

Induction accelerators are a unique source for high current, high-brightness, electron beams. A collaboration between the Lawrence Livermore National Laboratory (LLNL) and Lawrence Berkeley National Laboratory (LBNL) has been studying rf power sources based on the Relativistic Klystron Two-Beam Accelerator (RK-TBA) concept for several years [1], [2]. A major technical challenge to the successful operation of a full scale RK-TBA is the transport of the electron beam through several hundred meters of narrow aperture microwave extraction structures and induction accelerator cells. Demanding beam parameters are required of the electron source, an induction injector, to achieve the transport goals. A test facility, called the RTA, has been established at LBNL [3] to verify the analysis used in the design study. The primary effort of the facility is the construction of a prototype RK-TBA subunit that will permit the study of technical issues, system efficiencies, and costing. In this paper, we will discuss the development of the RTA electron source and it's pulsed power system, which has recently been constructed and is now undergoing testing. For this paper, the RTA injector refers only to the 1-MV gun and does not include the planned 1.8-MV accelerator section.

\section{RTA INJECTOR}

A major part of our effort during the past year has been towards the design and construction of an electron source with much lower emittance than typical induction injectors. The electron source will be a 3.5"-diameter, thermionic, flat-surface W-type cathode with a maximum shroud field stress of approximately $165 \mathrm{kV} / \mathrm{cm}$. An emission density of $20 \mathrm{~A} / \mathrm{cm}^{2}$ is required from the cathode to produce $1.2 \mathrm{kA}$ beam. The RTA injector, depicted in Fig. 1, has 72 induction cores, each driven at $14 \mathrm{kV}$. The voltage across the A-K gap is $1 \mathrm{MV}$. The cores are segmented radially to reduce the individual aspect $(\Delta \mathrm{r} / \Delta \mathrm{z})$ ratio. The lower aspect ratio reduces the variation in core impedance during the voltage pulse simplifying the pulse forming network (PFN) design. Fig. 2 is a photograph of the injector, shielded hall and electrical racks.

High-voltage tests (no beam) to full operational parameters have been successfully completed on the injector. In operation, a $500 \mathrm{kV}$ potential is developed across the two 30-cm-ID PYREX [4] insulators producing a $5.1 \mathrm{kV} / \mathrm{cm}$ average gradient along the insulator. The maximum field at the triple points, the intersection of insulator, vacuum, and metal, is designed to be less than $3.5 \mathrm{kV} / \mathrm{cm}$. Maximum surface field in the cathode half of the injector electrode is about $85 \mathrm{kV} / \mathrm{cm}$. The maximum field is about $116 \mathrm{kV} / \mathrm{cm}$ on the anode

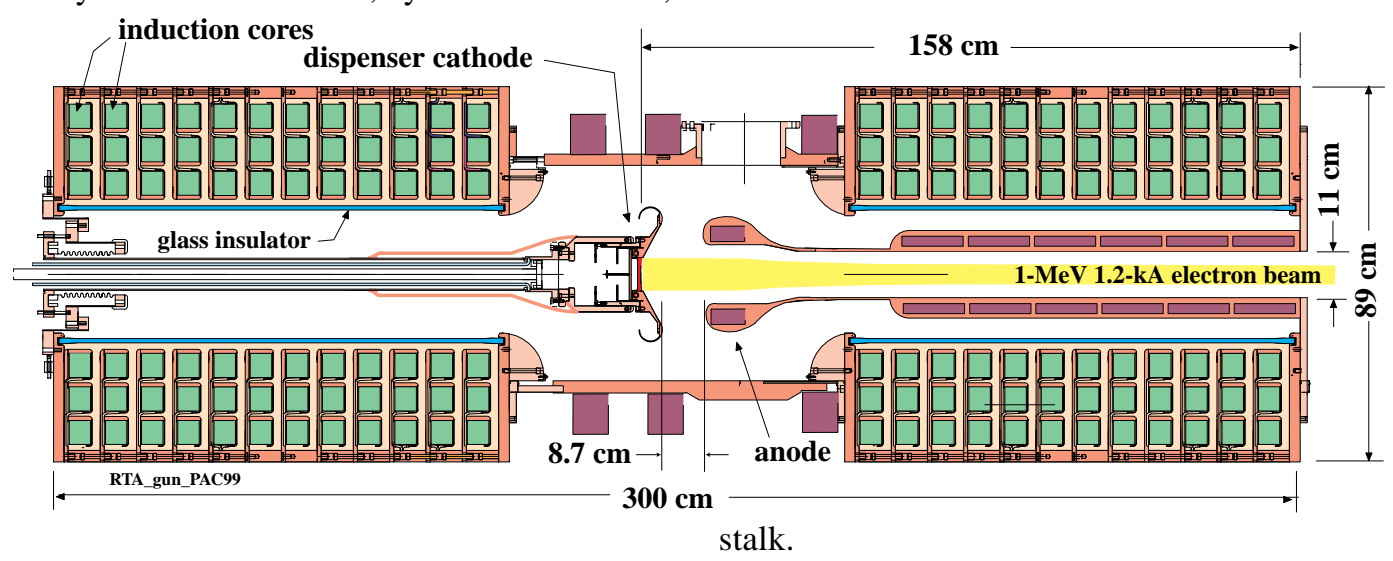

Figure 1. Schematic of the RTA injector depicting the 24 3-core cells, electrodes, glass insulators, and solenoids. 
Beam tests have recently commenced. The maximum A-K gap voltage has been kept below $400 \mathrm{kV}$ producing almost 200 A beam current while radiation surveys, subsystem checkouts, and cathode studies are performed. No electrical breakdowns have been observed at these lower voltages. Vacuum can be maintained in the high $10^{-8}$ Torr range with a cold cathode increasing into the low $10^{-7}$ Torr range during operations. Theoretical perveance for the installed A-K gap width is 1.0 upervs. Measured perveance is $\bullet 0.84 \mu$ pervs with the uncertainty in the upper bound due to the present voltage calibration.

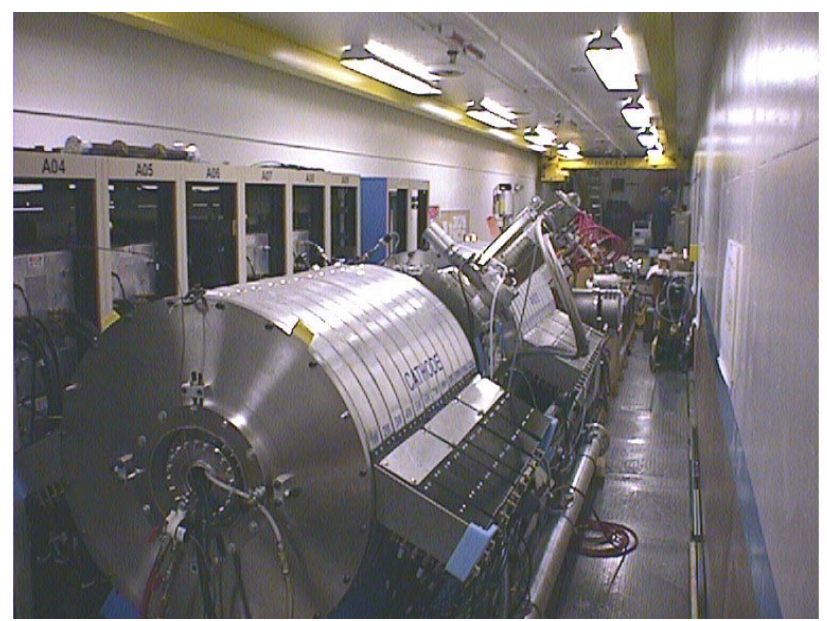

Figure 2. Photograph of the RTA injector looking from the cathode end of the injector down the beamline.

Initial beam focusing in the injector is accomplished by three large-bore air-core solenoids installed on the central pumping spool. The first solenoid is operated to null the magnetic field from the other solenoids at the cathode front surface. There are seven smaller solenoids located within the anode stalk to provide additional focusing to transport the beam to the end of the injector.

\section{PULSED POWER SYSTEM}

The injector's pulsed power system consists of a $20-\mathrm{kV}$ High-Voltage Power Supply, 6-kJ Energy Storage Bank, two Command Resonant Charging (CRC) Chassis, 24 Switched Pulse Forming Networks, and four Induction Core Reset Pulsers. Each PFN drives a single 3-core induction cell of the injector.

Segmenting the core in the induction cell and driving the individual core segments avoids a high-voltage stepup transformer. This reduces the developmental effort needed to achieve a "good" flattop pulse (minimal energy variation) with fast risetime and improves the efficiency of the overall pulsed power system. Our system of lowvoltage PFNs driving multiple core induction cells is similar to the system envisioned for the extraction section in the full-scale RK-TBA design. For the injector core material, we choose 20- $\mu$ m-thick 2605SC METGLAS [5]. For the RTA extraction section we will use a lower loss 2714AS METGLAS for the induction cores.

Design of the switched PFNs follows easily from published METGLAS core loss data [6]. A flux swing of $2.6 \mathrm{~T}$ in $400 \mathrm{~ns}$ (FWHM) results in a magnetization rate of $6.5 \mathrm{~T} / \mu \mathrm{s}$ for the injector cores. This rate generates a loss density of $1800 \mathrm{~J} / \mathrm{m}^{3}$, or a $30 \mathrm{~J}$ lost in a 3-core cell with $16.7 \times 10^{3} \mathrm{~cm}^{3}$ of 2605SC METGLAS. For an input voltage of $14 \mathrm{kV}$ applied for $400 \mathrm{~ns}$, these losses require that $5900 \mathrm{~A}$ be supplied to the cell. An additional $3600 \mathrm{~A}$ is required to supply beam current $(1200 \mathrm{~A} x$ 3 cores/cell), resulting in a total current of $9 \mathrm{kA}$. The required drive impedance for a cell is then $1.5 \Omega$.

Achieving the fast risetime necessary to minimise the volt-seconds required for the injector cores presented a challenge. Budget constraints coupled with the large availability of EEV CX1538 thyratrons from the ATA program at LLNL made these tubes an attractive option. However, their poor time rate of current change $(4 \mathrm{kA} / \mu \mathrm{s}$ rating) made them questionable for this application, which requires about $40 \mathrm{kA} / \mu \mathrm{s}$. A variety of techniques were tried to decrease the risetime. Each thyratron is located between two current sheets connecting the PFN output to the output cables to reduce the stray circuit inductance. In addition, the thyratron ionization time is substantially reduced by applying a 1-2 A pre-pulse to the keep-alive grid 300-400 ns prior to the arrival of the main control-grid pulse. We presently have risetimes less than $150 \mathrm{~ns}$ for all 24 cells. Since the thyratron turn-on time is voltage dependent, we are adjusting the trigger time of each individual tube. Faster risetimes were achieved with Triton F-130 ceramic thyratrons. An upgrade of the current thyratrons in the injector pulsed power system should allow us to achieve the design 100 -ns risetime.

At the 1-MV, 1.2-kA operating conditions we hope to produce a $\pm 1 \%$ injector voltage flat waveform for 120 ns. We will need to adjust the number of turns in appropriate sections of individual PFNs to achieve this goal. Insertion of ferrite material in the center of the inductors coils will allow additional small corrections to the waveform. There are 24 EEV CX1538 thyratrons used in the pulsed power system for the injector.

\section{RTA INJECTOR DIAGNOSTICS}

A variety of diagnostics will be used to determine the performance of the injector, both permanently installed monitors for general operations and temporary diagnostics specific to injector commissioning and troubleshooting.

\subsection{Current Measurements}

An accurate measurement of the emitted current from the cathode is required both for determining the performance of the injector and benchmarking codes. We have 
electrically isolated the cathode from the stalk, forcing the current to flow through several parallel, 0.25 inch wide, strips of $25-\mu \mathrm{m}$ thick stainless steel foil that act as current-viewing resistors (CVRs). The potential drop across the foil is measured and the current inferred. To improve the time response a parallel-strip shunt geometry is used where the foil is folded on itself to increase the resistance while lowering the series inductance. The beam dump is also electrically isolated similar to the cathode to allow the measurement of the total current deposited in the dump. Four CVRs, equally spaced azimuthally around the dump, are summed.

A resistive wall current monitor is located immediately following the injector. This monitor measures the potential drop of the return wall current across a known resistance generating a signal proportional to the current. The potential drop is measured at eight locations around the circumference of the beam tube permitting the measurement of total current and centroid position.

Magnetic pickup (B-dot) loops are available to be inserted in the transport section after the injector to determine the time derivative of the current pulse. The voltage induced on the loop can then be integrated to recover the current and centroid position. The advantage of the B-dot loops over the other current diagnostics is a higher frequency bandwidth.

\subsection{A-K Voltage and Beam Energy}

We are using two methods to determine the A-K voltage and infer the beam energy. The first method involves using resistive voltage dividers to measure the applied voltage to the induction cores at the power feed connections. Capacitive dV/dt pickup probes [7] are used for a more direct measurement of the A-K gap voltage and also to provide greater bandwidth with respect to the resistive dividers. We also hope to employ a conventional energy spectrometer comprised of an onaxis collimator, dipole magnet, scintillator, and viewing port to directly measure the beam energy.

\subsection{Current Density Profile}

The current density profile will be measured using Cherenkov radiation from intercepting foils. A primary concern with using foils is possible damage from beam energy deposition. Adjusting the repetition rate of the injector can control average heating of the foil. The difficulty is single shot heating where material can be melted and ejected before the heat is conducted away. To avoid damage to a thin quartz foil, we anticipate that the beam diameter must be greater than $2 \mathrm{~cm}$ for a $1-\mathrm{kA}$, 300-ns, relativistic electron beam.

The light generated at the beam/foil interaction will be recorded using both gated and streak cameras. The streak camera will be used principally to determine if the properties of the foil and/or beam change during the pulse. The significant levels of energy deposited in the foil could affect the dielectric constant or generate a surface plasma that could be confused as a variation in beam parameters.

\subsection{Emittance Measurement}

Measuring the beam emittance is expected to be very difficult as the beam is highly space charged dominated. A pepperpot emittance diagnostic has been constructed. The size of the apertures is the only variable for adjusting the relative contribution of emittance to space charge. For the designed RTA injector beam parameters, $1.2 \mathrm{kA}$, $1 \mathrm{MeV}$ and $100 \pi$-mm-mr, and using a $250-\mu \mathrm{m}$ aperture, the emittance term for the beamlets passing through the aperture plate is approximately an order of magnitude larger than the space charge term. Our aperture plate will consist of a rectangular pattern of 121 (11x11) 250- $\mu \mathrm{m}$ apertures with $7 \mathrm{~mm}$ spacing on a $500-\mu \mathrm{m}$ thick tungsten plate. The tungsten plate represents about two range thickness for $1-\mathrm{MeV}$ electrons. The beamlets will strike a phosphor coated foil located about $80 \mathrm{~cm}$ after the aperture and imaged with a gated camera.

\section{SUMMARY}

Initial beam tests have commenced on the RTA injector generating a 400-KeV, 200-A, 400-ns (FWHM) electron pulse. Full operations (1-MV, 1-kA) will commence after the completion of radiation surveys and ancillary system checkouts. Upcoming tests will stress characterization of the beam parameters particularly the emittance and current density profile.

\section{ACKNOWLEDGMENTS}

The work was performed under the auspices of the U.S. Department of Energy by LLNL under contract W-7405ENG-48, and by LBNL under contract AC0376SF00098. We thank Andy Sessler and Swapan Chattopadhyay for their support and guidance and thank Wayne Greenway, Don Lester, William Strelo, and Bob Candelario for their outstanding technical support.

\section{REFERENCES}

1. Sessler, A.M. and Yu, S.S., "Relativistic Klystron Two-Beam Accelerator," Phys. Rev. Lett. 54, 889 (1987).

2. Westenskow, G.A., and Houck, T.L., "Relativistic Klystron Two-Beam Accelerator," IEEE Trans. on Plasma Sci., 22, 750 (1994).

3. Houck, T.L., and Westenskow, G.A., "Prototype Microwave Source for a Relativistic Klystron TwoBeam Accelerator" IEEE Trans. on Plasma Sci., 24, 938 (1996).

4. Registered name of Corning Glass Works.

5. Registered name of AlliedSignal Corporation.

6. Smith, C., and Barberi, L., "Dynamic Magnetization of Metallic Glasses," in Proc. of the 5th. IEEE Int'l Pulsed Power Conf., 1985.

7. Houck, T.L., et al., "Diagnostics for a 1.2-kA, 1-MV Electron Induction Injector," Proc. of the $8^{\text {th }}$ Beam Instrumentation Workshop, SLAC, 1998. 